\title{
Efficacy of the Delayed Use of Low-dose Aspirin in Intravenous Immunoglobulin Therapy for Acute-phase Kawasaki Disease
}

\author{
Toshimasa Nakada
}

\section{ABSTRACT}

The mainstay of current standard therapy for acute-phase Kawasaki disease (KD) is intravenous immunoglobulin (IVIG) therapy at $2 \mathrm{~g} / \mathrm{kg}$. However, the efficacy of combining medium- or high-dose aspirin with IVIG therapy at $2 \mathrm{~g} / \mathrm{kg}$ has not been fully investigated. Some studies suggested that aspirin may inhibit coronary artery lesion (CAL) prevention in IVIG therapy and that the delayed use of aspirin in IVIG therapy may be beneficial for the suppression of CALs and prevention of coronary artery stenosis in patients with KD. The efficacy of the delayed use of lowdose aspirin in IVIG therapy for acute-phase KD remains unclear. Therefore, this retrospective study aimed to assess the efficacy of the delayed use of low-dose aspirin, when combined with IVIG therapy for acute-phase KD. Data were obtained from $193 \mathrm{KD}$ patients who underwent acute-phase treatment from January 2009 to October 2020 and IVIG therapy at $2 \mathrm{~g} / \mathrm{kg}$ with the delayed use of aspirin/flurbiprofen. The patients were divided into three groups: (1) low-dose group, in which 40 patients received low-dose aspirin (5 mg/kg/day); (2) medium-dose group, in which 90 patients received medium-dose aspirin (30 mg/kg/day); and (3) flurbiprofen group, in which 63 patients received flurbiprofen (3-5 $\mathrm{mg} / \mathrm{kg} /$ day). KD patients with liver damage or those present during influenza season underwent flurbiprofen therapy between January 2009 and November 2017. All patients except one received low-dose aspirin after December 2017. The serum albumin level (median 3.40 vs. $3.30 \mathrm{~g} / \mathrm{dL}, \mathrm{P}=$ 0.026) and Egami score (median 1.0 vs. 2.0, $\mathrm{P}<0.001$ ) before the initial treatment were significantly different between the medium-dose group and the flurbiprofen group. The rates of initial IVIG therapy resistance $\mathbf{( 2 5 . 0 \%}$ vs. $18.9 \%$ vs. $25.4 \%, P=0.790)$, rescue therapy $(17.5 \%$ vs. $8.9 \%$ vs. $17.5 \%$, $\mathrm{P}=\mathbf{0 . 7 2 1})$, and CALs $(5.0 \%$ vs. $0.0 \%$ vs. $4.8 \%, P=0.713)$ were similar among the low-dose, medium-dose, and flurbiprofen groups. Overall, the efficacy of the delayed use of low-dose aspirin was similar to that of the delayed use of medium-dose aspirin/flurbiprofen in IVIG therapy for acute-phase KD.

Keywords: aspirin, coronary artery lesions, flurbiprofen, intravenous immunoglobulin therapy, Kawasaki disease.

\section{INTRODUCTION}

Kawasaki disease (KD) is a form of acute febrile systemic vasculitis that primarily affects children younger than 5 years [1]. Coronary artery lesions (CALs) are a severe complication of KD [2].

The mainstay of the current standard therapy for acutephase KD is intravenous immunoglobulin (IVIG) therapy at $2 \mathrm{~g} / \mathrm{kg}$ with the concomitant use of medium-/high-dose aspirin. Moreover, evidence has established its efficacy in CAL suppression [3]. However, the efficacy of combining medium- or high-dose aspirin with IVIG therapy at $2 \mathrm{~g} / \mathrm{kg}$ has not been fully investigated [4]. A randomized controlled trial on the effectiveness of IVIG monotherapy versus IVIG therapy combined with high-dose aspirin in the acute KD stage is ongoing [5]. Some studies suggested that aspirin may inhibit CAL prevention in IVIG therapy and that the delayed use of aspirin (DUA) for IVIG therapy may be
Published Online: February 4, 2021

ISSN: $2593-8339$

DOI: $10.24018 /$ ejmed.2021.3.1.691

\section{T. Nakada*}

Department of Pediatrics, Aomori,

Prefectural Central Hospital, Japan. (e-mail: toshimasanakada ${ }^{@}$ yahoo.co.jp)

*Corresponding Author beneficial for the suppression of CALs and prevention of coronary artery stenosis in patients with KD [6]-[9]. Furthermore, a recent study showed favorable medium-term outcomes of CALs in KD patients who underwent IVIG therapy at $2 \mathrm{~g} / \mathrm{kg}$ with DUA [10].

Moreover, the optimal dose of aspirin for the acute-phase treatment of KD has not been determined yet [11], [12]. Some studies showed that the use of low-dose aspirin (3$5 \mathrm{mg} / \mathrm{kg} /$ day) may be as effective as the use of medium/high-dose aspirin ( $\geq 30 \mathrm{mg} / \mathrm{kg} /$ day) in the initial treatment of KD [13], [14]. The efficacy of the delayed use of lowdose aspirin in IVIG therapy for acute-phase KD remains unclear. Therefore, this retrospective study aimed to assess the efficacy of the delayed use of low-dose aspirin when combined with IVIG therapy for acute-phase KD. 


\section{PARTICIPANTS AND METHODS}

Our institutional ethics committee approved the study protocol and waived the requirement of patient consent because of the retrospective nature of the study.

Data were obtained from $193 \mathrm{KD}$ patients who underwent acute-phase treatment from January 2009 to October 2020 and IVIG therapy at $2 \mathrm{~g} / \mathrm{kg}$ with the delayed use of aspirin/flurbiprofen. The patients were divided into three groups: (1) low-dose group, in which 40 patients received low-dose aspirin (5 mg/kg/day); (2) medium-dose group, in which 90 patients received medium-dose aspirin (30 $\mathrm{mg} / \mathrm{kg} /$ day); and (3) flurbiprofen group, in which 63 patients received flurbiprofen $(3-5 \mathrm{mg} / \mathrm{kg} /$ day $)$.

A total of six patients with complications including CAL before the initial therapy were excluded.

KD was diagnosed based on the criteria (Japanese, fifth edition) mentioned in the diagnostic guidelines for KD until August 2019 and on the revised criteria (Japanese, sixth edition) from September 2019 [2], [15]. IVIG resistance was defined as a fever that persisted or reappeared $24 \mathrm{~h}$ after the first-line treatment [3]. Presentations of KD were considered as relapses when a second episode appeared within 2 months of the first one. [16], [17]. The Egami score, a risk score for predicting IVIG resistance based on clinical findings such as age, days of illness, platelet count, alanine aminotransferase level, and C-reactive protein level, was evaluated before the initial IVIG therapy [18]. The outcomes included the rates of IVIG resistance, rescue therapy, and CALs.

\section{A. Initial Therapy}

During the study period, a single IVIG infusion at $2 \mathrm{~g} / \mathrm{kg} /$ dose was given as initial therapy starting on Day 5 of the illness, whenever possible [10]. Patients without inflammation or complications upon presentation underwent acute-phase therapy without IVIG [10]. Between January 2009 and November 2017, anti-inflammatory drugs (aspirin or flurbiprofen) were initiated within $24 \mathrm{~h}$ after the initial IVIG infusion ended [6]. Aspirin and flurbiprofen were started at 30 and $3-5 \mathrm{mg} / \mathrm{kg} /$ day, respectively, and decreased to $5-10$ and $3 \mathrm{mg} / \mathrm{kg} / \mathrm{day}$, respectively, once the patient was afebrile [6]. Each treating physician chose aspirin or flurbiprofen after considering the patient's liver function and the risk of Reye syndrome during influenza season between January 2009 and November 2017. After December 2017 , low-dose aspirin $(5 \mathrm{mg} / \mathrm{kg} /$ day) was begun on Days $8-10$ of the illness after the completion of IVIG infusion, including the second course of therapy [10].

\section{B. Rescue Therapy}

The decision to use rescue therapies in resistant patients was made 48 to $72 \mathrm{~h}$ after the completion of the initial IVIG infusion. Physicians made this decision using comprehensive clinical parameters, including body temperature, major KD symptoms, general condition, and laboratory data [10]. Course 2 of therapy comprised rescue IVIG infusion at $2 \mathrm{~g} / \mathrm{kg} / \mathrm{dose}$, and course 3 was an ulinastatin infusion, third course of IVIG therapy, or plasma exchange [10].

\section{Diagnosis of $C A L$}

CALs were diagnosed using echocardiography based on the Japanese criteria reported by Kobayashi et al [19]. CAL was diagnosed if any examination showed an internal lumen diameter of $\geq 3 \mathrm{~mm}$ in a patient younger than 5 years or a diameter of $\geq 4 \mathrm{~mm}$ in a patient older than 5 years if the internal diameter of a segment was at least 1.5 times larger than that of an adjacent segment or if the lumen appeared irregular. A transient CAL was defined as the disappearance of a CAL within 30 days of the illness.

\section{Statistical Analysis}

Statistical analyses were conducted using Stat Flex Version 6 for Windows (Artech Co., Ltd., Osaka, Japan). Chi-square test, Fisher exact test, Mann-Whitney U test, and Kruskal-Wallis test were used accordingly, with sample size considerations. $\mathrm{P}<0.05$ was considered statistically significant.

\section{RESULTS}

The rate of the era of onset after 2018 between the lowdose and medium-dose groups, and that between the lowdose group and the flurbiprofen group were significantly different (Tables I and II). The Egami score of the flurbiprofen group was significantly higher than that of the low-dose and medium-dose groups (Tables II and III). Furthermore, the Egami scores of the low-dose, mediumdose, and flurbiprofen groups were significantly different among the three groups (Table IV). The serum albumin level of the flurbiprofen group was significantly lower than that of the medium-dose group (Table III). The rates of the initial IVIG therapy resistance, rescue therapy, and CALs were similar among the low-dose, medium-dose, and flurbiprofen groups (Tables I, II, III, and IV).

\section{DISCUSSION}

The main finding of this study was that the rates of initial IVIG therapy resistance, rescue therapy, and CALs were similar among the low-dose, medium-dose, and flurbiprofen groups (Tables I, II, III, and IV). This finding indicated that the efficacy of the delayed use of low-dose aspirin was similar to that of the delayed use of medium-dose aspirin/flurbiprofen in IVIG therapy for acute-phase KD.

Some studies showed that the use of low-dose aspirin (3$5 \mathrm{mg} / \mathrm{kg} /$ day) may be as effective as the use of medium/high-dose aspirin ( $\geq 30 \mathrm{mg} / \mathrm{kg} /$ day) for the initial treatment of KD [13], [14], [20]-[24].

Current evidence based on a meta-analysis demonstrated that treatment combined with low-dose aspirin compared with high-dose aspirin ( $\geq 30 \mathrm{mg} / \mathrm{kg} / \mathrm{day}$ ) for the acute-phase treatment of KD showed no significant difference in the incidence of CAL, the risk of IVIG therapy resistance, or the length of fever or hospital stay [14]. According to this metaanalysis, the risk ratio of the low-dose aspirin group regarding CAL development was less than 1.0 in five of six studies compared with that of the high-dose aspirin group [13], [14], [20]-[24]. Moreover, one study showed that the adjusted risk difference was statistically significant, favoring the low-dose aspirin group (the low-dose vs. high-dose group: $-4.0 \%$ vs. $-1.9 \%, \mathrm{P}$ value $=0.024$ ) for medium or larger CAL caused by KD [13]. This was the result when combining the concomitant use of aspirin with IVIG therapy 
[13].

Two studies from Korea reported the outcomes of CAL in patients who underwent IVIG therapy at $2 \mathrm{~g} / \mathrm{kg}$ with delayed use of low-dose aspirin for the acute-phase treatment of KD [8], [25]. One study showed that no patients had CALs with an internal diameter of $\geq 6 \mathrm{~mm}$, which indicates a risk of stenotic lesions [8]. Another study showed that the prevalence of CALs in the patients who underwent IVIG therapy at $2 \mathrm{~g} / \mathrm{kg}$ with the delayed use of low-dose aspirin was similar to the prevalence in those who underwent IVIG therapy at $2 \mathrm{~g} / \mathrm{kg}$ with the concomitant use of high-dose aspirin (3.9\% vs. $7.8 \%, \mathrm{P}=0.514)$ [25]. Furthermore, a study using the data of the nationwide survey of KD conducted in Korea showed that the prevalence of CALs in 509 subjects who received low-dose aspirin was significantly lower than the prevalence in 7947 subjects who received medium-/high-dose aspirin during the acute febrile phase [21]. A recent meta-analysis showed that prescribing low-dose or no aspirin in the acute-phase KD might be associated with the decreased incidence of CAL [26].

Regarding the favorable outcomes of CAL in the lowdose group, those findings are consistent with those of the present study (Tables I, II, and IV). In our previous study, the findings suggested that the concomitant use of mediumdose aspirin/flurbiprofen may inhibit CAL prevention in IVIG therapy, whereas the delayed use of those antiinflammatory drugs in initial IVIG therapy may be beneficial for the suppression of CALs in patients with KD [6]. Moreover, recent studies demonstrated the usefulness of IVIG therapy at $2 \mathrm{~g} / \mathrm{kg}$ with DUA for the prevention of coronary artery stenosis and the favorable medium-term outcomes in patients with KD [9], [10].

A recent report regarding platelet activation characteristics and the effect of antiplatelet therapy for patients with acute $\mathrm{KD}$ using a newly automated flow chamber system to evaluate platelet aggregate formation under shear stress condition showed that the patients developed early and unstable platelet aggregates regardless of aspirin use at different dosages and the use of an alternative drug (flurbiprofen) [27], [28]. Furthermore, the characteristics of platelet thrombus formation under a high shear condition in children with KD were not specific compared with those in febrile child controls [27]. Those findings support the effectiveness of KD treatment without aspirin or with low-dose aspirin [27].

Although high-dose aspirin is generally well-tolerated in children, reports of adverse effects, including gastrointestinal bleeding and Reye syndrome, have been documented [29], [30]. Meanwhile, low-dose aspirin has not been associated with Reye syndrome [31], is administered once daily, and may be better tolerated. Given these potential advantages, an investigation into the outcomes of children treated with low-dose aspirin is important [32]. Some studies suggested that high-dose aspirin does not reduce CALs, with a surprising possibility that aspirin might be associated with a higher incidence of CALs [6], [7], [13], [20]-[26], [33]. A recent meta-analysis recommended a low-dose aspirin plus IVIG as the first-line therapy in the initial treatment of KD [12].

Previous studies found that treatment with IVIG alone without aspirin in the acute stage of KD did not affect the response rate of IVIG treatment [34], [35]. Furthermore, the recent meta-analysis indicated that the rates of nonresponders between the low-dose and high-dose aspirin groups were not statistically different [14]. This finding was consistent with the results of the present study: the rates of non-responders were similar among the three groups (Tables I, II, III, and IV). The decision for rescue therapy was comprehensively made according to clinical parameters, including body temperature, major KD symptoms, general condition, and laboratory data, after initial therapy in the present study [10], [36]. The similar rates of non-responders and rescue therapy among the three groups in this study may also be due to this strategy.

KD relapse is a risk factor for CAL development [17], [37]. A study showed that the rates of KD relapse and CAL development were similar between the patients who were treated with low-dose aspirin and those who were treated with high-dose aspirin [32]. Those findings were consistent with those of the present study: the rates of KD relapse and CAL development were similar among the three groups (Tables I, II, III, and IV).

The use of high-dose aspirin has a risk of salicylateinduced hepatitis and Reye syndrome in acute-phase of KD [11], [29], [38]. Flurbiprofen has been used in KD patients with elevated liver enzyme levels or during an influenza epidemic in Japan, and Reye syndrome was not considered as one of the adverse effects of flurbiprofen [27], [39]. A study on platelet aggregate formation under shear stress conditions supports the treatment for acute-phase KD using flurbiprofen instead of medium-dose aspirin as antiplatelet therapy as well as low-dose aspirin [27]. In fact, the efficacy of flurbiprofen was similar to those of low-/medium-dose aspirin, and no patients had salicylate-induced hepatitis or Reye syndrome in the present study.

An increase in liver enzyme levels is a risk factor for IVIG therapy resistance and CALs [18], [19]. In the present study, KD patients with liver damage or those present during influenza season received flurbiprofen therapy between January 2009 and November 2017. Low serum albumin level indicates severe arteritis in the acute-phase of $\mathrm{KD}$, and is considered a risk factor for IVIG resistance and CAL development [40], [41]. The higher Egami score and lower serum albumin levels before initial therapy in the flurbiprofen group suggested more severe KD patients in this group (Tables II, III, and IV). The lower rate of initial IVIG therapy resistance, rescue therapy, and CALs in the medium-dose group may be due to the different severity of the disease before initial therapy because patients in the medium-dose group and those in the flurbiprofen group received IVIG therapy in the same period (between January 2009 and November 2017).

The limitations of this study include the small sample size and the retrospective study design.

In conclusion, the rates of initial IVIG therapy resistance, rescue therapy, and CALs were similar among the low-dose, medium-dose, and flurbiprofen groups. Furthermore, the efficacy of the delayed use of low-dose aspirin may be similar to that of the delayed use of medium-dose aspirin/flurbiprofen in IVIG therapy at $2 \mathrm{~g} / \mathrm{kg}$ for acutephase KD. 
TABLE I: COMPARISON OF CLINICAL FINDINGS, TREATMENTS, AND OUTCOMES BETWEEN THE LOW-DOSE GROUP AND THE MEDIUM-DOSE

\begin{tabular}{|c|c|c|c|}
\hline Variables & $\begin{array}{l}\text { Low-dose group } \\
(\mathrm{n}=40)\end{array}$ & $\begin{array}{l}\text { Medium-dose } \\
\text { group }(n=90)\end{array}$ & P-value \\
\hline \multicolumn{4}{|l|}{ Era of onset } \\
\hline After 2018 & $36(90.0 \%)$ & $1(1.1 \%)$ & $<0.001$ \\
\hline Male gender & $21(52.5 \%)$ & $43(47.8 \%)$ & 0.619 \\
\hline $\begin{array}{l}\text { Age at KD onset } \\
\text { (months) }\end{array}$ & $28.0(150-44.0)$ & $26.0(14.0-51.0)$ & 0.776 \\
\hline Incomplete type & $5(12.5 \%)$ & $12(13.3 \%)$ & 0.897 \\
\hline Egami score & $1.0(0.5-2.0)$ & $1.0(1.0-2.0)$ & 0.394 \\
\hline $\mathrm{CRP}(\mathrm{mg} / \mathrm{dL})$ & $\begin{array}{c}5.935(4.095- \\
8.960)\end{array}$ & $\begin{array}{c}6.585(3.640- \\
11.550)\end{array}$ & 0.661 \\
\hline Albumin (g/dL) & $3.40(3.10-3.60)$ & $\begin{array}{c}3.40(3.20-3.70) \\
(\mathrm{n}=88)\end{array}$ & 0.328 \\
\hline NLR & $2.91(1.55-4.70)$ & $\begin{array}{c}2.46(1.38-4.58) \\
(\mathrm{n}=82)\end{array}$ & 0.571 \\
\hline $\begin{array}{c}\text { Start day of illness } \\
\text { of initial IVIG } \\
\text { therapy }\end{array}$ & $5.0(5.0-6.0)$ & $5.0(5.0-6.0)$ & 0.882 \\
\hline Non-responder & $10(25.0 \%)$ & $17(18.9 \%)$ & 0.428 \\
\hline Rescue therapy & $7(17.5 \%)$ & $8(8.9 \%)$ & 0.232 \\
\hline For non-responder & $5(12.5 \%)$ & $7(7.8 \%)$ & 0.512 \\
\hline For relapse & $1(2.5 \%)$ & $1(1.1 \%)$ & 1.000 \\
\hline $\begin{array}{c}\text { For responder } \\
\text { CAL }\end{array}$ & $1(2.5 \%)$ & $0(0.0 \%)$ & 0.308 \\
\hline $\begin{array}{l}\text { Less than one } \\
\text { month after KD } \\
\text { onset }\end{array}$ & $2(5.0 \%)$ & $0(0.0 \%)$ & 0.093 \\
\hline $\begin{array}{c}\text { One month after KD } \\
\text { onset }\end{array}$ & $1(2.5 \%)$ & $0(0.0 \%)$ & 0.308 \\
\hline
\end{tabular}

Data are presented as $\mathrm{n}(\%)$ or median (interquartile range).

KD: Kawasaki disease, CRP: C-reactive protein, NLR: neutrophil-tolymphocyte ratio, IVIG: intravenous immunoglobulin, CAL: coronary artery lesion.
TABLE III: COMPARISON OF CLINICAL FINDINGS, TREATMENTS, AND OUTCOMES BETWEEN THE MEDIUM-DOSE GROUP AND THE FLURBIPROFEN GROUP

\begin{tabular}{|c|c|c|c|}
\hline Variables & $\begin{array}{l}\text { Medium-dose } \\
\text { group }(n=90)\end{array}$ & $\begin{array}{c}\text { Flurbiprofen } \\
\text { group }(n=63)\end{array}$ & P-value \\
\hline \multicolumn{4}{|l|}{ Era of onset } \\
\hline After 2018 & $1(1.1 \%)$ & $0(0.0 \%)$ & 1.000 \\
\hline Male gender & $43(47.8 \%)$ & $34(54.0 \%)$ & 0.451 \\
\hline $\begin{array}{l}\text { Age at KD onset } \\
\text { (months) }\end{array}$ & $26.0(14.0-51.0)$ & $24.0(14.0-43.3)$ & 0.671 \\
\hline Incomplete type & $12(13.3 \%)$ & $10(15.9 \%)$ & 0.660 \\
\hline Egami score & $1.0(1.0-2.0)$ & $2.0(1.0-3.0)$ & $<0.001$ \\
\hline CRP (mg/dL) & $\begin{array}{c}6.585(3.640- \\
11.550)\end{array}$ & $\begin{array}{c}6.360(3.820- \\
10.280)\end{array}$ & 0.947 \\
\hline Albumin (g/dL) & $\begin{array}{c}3.40(3.20-3.70) \\
(\mathrm{n}=88)\end{array}$ & $3.30(3.10-3.50)$ & 0.026 \\
\hline NLR & $\begin{array}{c}2.46(1.38-4.58) \\
(n=82)\end{array}$ & $\begin{array}{c}3.43(1.70-6.90) \\
(n=57)\end{array}$ & 0.066 \\
\hline \multicolumn{4}{|l|}{ tart day of illness } \\
\hline $\begin{array}{l}\text { of initial IVIG } \\
\text { therapy }\end{array}$ & $5.0(5.0-6.0)$ & $5.0(5.0-6.0)$ & 0.895 \\
\hline Non-responder & $17(18.9 \%)$ & $16(25.4 \%)$ & 0.335 \\
\hline Rescue therapy & $8(8.9 \%)$ & $11(17.5 \%)$ & 0.114 \\
\hline For non-responder & $7(7.8 \%)$ & $8(12.7 \%)$ & 0.314 \\
\hline For relapse & $1(1.1 \%)$ & $3(4.8 \%)$ & 0.306 \\
\hline $\begin{array}{c}\text { For responder } \\
\text { CAL }\end{array}$ & $0(0.0 \%)$ & $0(0.0 \%)$ & 1.000 \\
\hline $\begin{array}{l}\text { Less than one } \\
\text { month after KD } \\
\text { onset }\end{array}$ & $0(0.0 \%)$ & $3(4.8 \%)$ & 0.068 \\
\hline $\begin{array}{c}\text { One month after } \\
\text { KD onset }\end{array}$ & $0(0.0 \%)$ & $1(1.6 \%)$ & 0.412 \\
\hline
\end{tabular}

Data are presented as $\mathrm{n}(\%)$ or median (interquartile range).

KD: Kawasaki disease, CRP: C-reactive protein, NLR: neutrophil-tolymphocyte ratio, IVIG: intravenous immunoglobulin, CAL: coronary artery lesion.

TABLE IV: COMPARISON OF CLINICAL FINDINGS, TREATMENTS, AND

OUTCOMES BETWEEN THE LOW-DOSE GROUP AND THE FLURBIPROFEN

\begin{tabular}{|c|c|c|c|}
\hline \multicolumn{4}{|c|}{ GROUP } \\
\hline Variables & $\begin{array}{c}\text { Low-dose group } \\
(\mathrm{n}=40)\end{array}$ & $\begin{array}{l}\text { Flurbiprofen } \\
\text { group }(n=63)\end{array}$ & P-value \\
\hline Era of onset & & & \\
\hline After 2018 & $36(90.0 \%)$ & $0(0.0 \%)$ & $<0.001$ \\
\hline Male gender & $21(52.5 \%)$ & $34(54.0 \%)$ & 0.884 \\
\hline $\begin{array}{c}\text { Age at KD onset } \\
\text { (months) }\end{array}$ & $28.0(15.0-44.0)$ & $24.0(14.0-43.3)$ & 0.895 \\
\hline Incomplete type & $5(12.5 \%)$ & $10(15.9 \%)$ & 0.636 \\
\hline Egami score & $1.0(0.5-2.0)$ & $2.0(1.0-3.0)$ & 0.002 \\
\hline $\mathrm{CRP}(\mathrm{mg} / \mathrm{dL})$ & $\begin{array}{c}5.935(4.095- \\
8.960)\end{array}$ & $\begin{array}{c}6.360(3.820- \\
10.280)\end{array}$ & 0.797 \\
\hline Albumin (g/dL) & $3.40(3.10-3.60)$ & $3.30(3.10-3.50)$ & 0.385 \\
\hline NLR & $2.91(1.55-4.70)$ & $\begin{array}{c}3.43(1.70-6.90) \\
(\mathrm{n}=57)\end{array}$ & 0.332 \\
\hline $\begin{array}{c}\text { Start day of illness } \\
\text { of initial IVIG } \\
\text { therapy }\end{array}$ & $5.0(5.0-6.0)$ & $5.0(5.0-6.0)$ & 0.804 \\
\hline Non-responder & $10(25.0 \%)$ & $16(25.4 \%)$ & 0.964 \\
\hline Rescue therapy & $7(17.5 \%)$ & $11(17.5 \%)$ & 0.996 \\
\hline For non-responder & $5(12.5 \%)$ & $8(12.7 \%)$ & 0.976 \\
\hline For relapse & $1(2.5 \%)$ & $3(4.8 \%)$ & 0.656 \\
\hline $\begin{array}{c}\text { For responder } \\
\text { CAL }\end{array}$ & $1(2.5 \%)$ & $0(0.0 \%)$ & 0.388 \\
\hline $\begin{array}{c}\text { Less than one } \\
\text { month after KD } \\
\text { onset }\end{array}$ & $2(5.0 \%)$ & $3(4.8 \%)$ & 1.000 \\
\hline $\begin{array}{l}\text { One month after } \\
\text { KD onset }\end{array}$ & $1(2.5 \%)$ & $1(1.6 \%)$ & 1.000 \\
\hline
\end{tabular}

Data are presented as n (\%) or median (interquartile range).

KD: Kawasaki disease, CRP: C-reactive protein, NLR: neutrophil-tolymphocyte ratio, IVIG: intravenous immunoglobulin, CAL: coronary artery lesion.

\section{OUTCOMES AMONG THE THREE GROUPS}

\begin{tabular}{ccccc} 
Variables & $\begin{array}{c}\text { Low-dose } \\
\text { group }(\mathrm{n}=40)\end{array}$ & $\begin{array}{c}\text { Medium- } \\
\text { dose group } \\
(\mathrm{n}=90)\end{array}$ & $\begin{array}{c}\text { Flurbiprofen } \\
\text { group } \\
(\mathrm{n}=63)\end{array}$ & $\begin{array}{c}\text { P- } \\
\text { value }\end{array}$ \\
\hline Egami score & $1.0(0.5-2.0)$ & $1.0(1.0-2.0)$ & $\begin{array}{c}2.0 \\
(1.0-3.0)\end{array}$ & 0.001 \\
Albumin (g/dL) & 3.40 & 3.40 & 3.30 & 0.082 \\
Non-responder & $10(25.0 \%)$ & $17(18.9 \%)$ & $16(25.4 \%)$ & 0.790 \\
Rescue therapy & $7(17.5 \%)$ & $8(8.9 \%)$ & $11(17.5 \%)$ & 0.721 \\
$\begin{array}{c}\text { For non- } \\
\text { responder }\end{array}$ & $5(12.5 \%)$ & $7(7.8 \%)$ & $8(12.7 \%)$ & 0.794 \\
$\begin{array}{c}\text { For relapse } \\
\text { For responder }\end{array}$ & $1(2.5 \%)$ & $1(1.1 \%)$ & $3(4.8 \%)$ & 0.348 \\
$\begin{array}{c}\text { CAL } \\
\text { Less than one }\end{array}$ & $1(2.5 \%)$ & $0(0.0 \%)$ & $0(0.0 \%)$ & 0.138 \\
month after KD & $2(5.0 \%)$ & $0(0.0 \%)$ & $3(4.8 \%)$ & 0.713 \\
$\begin{array}{c}\text { onset } \\
\text { One month after }\end{array}$ & $1(2.5 \%)$ & $0(0.0 \%)$ & $1(1.6 \%)$ & 0.868 \\
KD onset & & & & \\
\hline
\end{tabular}

Data are presented as $\mathrm{n}(\%)$ or median (interquartile range).

KD: Kawasaki disease, CRP: C-reactive protein, NLR: neutrophil-tolymphocyte ratio, IVIG: intravenous immunoglobulin, CAL: coronary artery lesion.

\section{ACKNOWLEDGMENT}

I would like to thank all of those who were involved in the medical management of the patients included in this study, and Enago (www.enago.jp) for the English language review. 


\section{REFERENCES}

[1] Kawasaki T, Kosaki F, Okawa S, Shigematsu I, Yanagawa H. A new infantile acute febrile mucocutaneous lymph node syndrome (MLNS) prevailing in Japan. Pediatrics 1974; 54: 271-6.

[2] Fukazawa R, Kobayashi J, Ayusawa M, Hamada H, Miura M, Mitani Y, et al. JCS/JSCS 2020 Guideline on Diagnosis and Management of Cardiovascular Sequelae in Kawasaki Disease. Circ J 2020; 84: 1348 407. doi:10.1253/circj.CJ-19-1094.

[3] Rearch Committee of the Japanese Society of Pediatric Cardiology; Cardiac Surgery Committee for Development of Guidelines for Medical Treatment of Acute Kawasaki Disease. Guidelines for medical treatment of acute Kawasaki disease: report of the Research Committee of the Japanese Society of Pediatric Cardiology and Cardiac Surgery (2012 revised version). Pediatr Int 2014; 56: 135-58. https://doi.org/10.1111/ped.12317.

[4] McCrindle BW, Tierney ESS. Acute treatment for Kawasaki disease: challenges for current and future therapies. J Pediatr 2017; 184: 7-10. DOI: 10.1016/j.jpeds.2017.01.072.

[5] Kuo HC, Guo MM, Lo MH, Hsieh KS, Huang YH. Effectiveness of intravenous immunoglobulin alone and intravenous immunoglobulin combined with high-dose aspirin in the acute stage of Kawasaki disease: study protocol for a randomized controlled trial. BMC Pediatr. 2018; 18: 200. https://doi.org/10.1186/s12887-018-1180-1.

[6] Nakada T. Effects of anti-inflammatory drugs on intravenous immunoglobulin therapy in the acute phase of Kawasaki disease. Pediatr Cardiol 2015; 36: 335-9. DOI 10.1007/s00246-014-1010-7.

[7] Lau AC, Duong TT, Ito S, Yeung RS. Intravenous immunoglobulin and salicylate differentially modulate pathogenic processes leading to vascular damage in a model of Kawasaki disease. Arthritis Rheum 2009; 60: 2131-41. https://doi.org/10.1002/art.24660

[8] Cho HJ, Bak SY, Kim SY, Yoo R, Baek HS, Yang S, et al. High neutrophil: lymphocyte ratio is associated with refractory Kawasaki $\begin{array}{lllll}\text { disease. Pediatr Int 2017; 59: 669-74. } & \end{array}$ https://doi.org/10.1111/ped.13240|.

[9] Nakada T. Acute phase treatment for prevention of coronary artery stenosis caused in Kawasaki disease: a single center retrospective study. Journal of Advanced Research in Medicine 2018; 5(4): 1-7. https://doi.org/10.24321/2349.7181.201818.

[10] Nakada T. Acute Phase Treatment and Medium-Term Outcomes in Kawasaki Disease. European Journal of Medical and Health Sciences 2020; 2 (4), August: $1-7$ http://dx.doi.org/10.24018/ejmed.2020.2.4.419.

[11] Kwon JE, Roh DE, Kim YH. The Impact of Moderate-Dose Acetylsalicylic Acid in the Reduction of Inflammatory Cytokine and Prevention of Complication in Acute Phase of Kawasaki Disease: The Benefit of Moderate-Dose Acetylsalicylic Acid. Children 2020, 7, 185; doi:10.3390/children7100185.

[12] Jia X, Du X, Bie S, Li X, Bao Y, Jiang M. What dose of aspirin should be used in the initial treatment of Kawasaki disease? A metaanalysis. Rheumatology 2020; $59 \quad$ (8): 1826-33. https://doi.org/10.1093/rheumatology/keaa050.

[13] Dallaire F, Fortier-Morissette Z, Blais S, Dhanrajani A, Basodan D, Renaud C, et al. Aspirin Dose and Prevention of Coronary Abnormalities in Kawasaki Disease. Pediatrics 2017; 139: pii: e20170098.

[14] Zheng X, Yue P, Liu L, Tang C, Ma F, Zhang Y, et al. Efficacy between low and high dose aspirin for the initial treatment of Kawasaki disease: Current evidence based on a meta-analysis. PLoS ONE 2019; 14(5): $\quad$ e0217274. https://doi.org/10.1371/journal.pone.0217274.

[15] Ayusawa M, Sonobe T, Uemura S, Ogawa S, Nakamura Y, Kiyosawa $\mathrm{N}$, et al. Revision of diagnostic guidelines for Kawasaki disease (the 5 th revised edition). Pediatr Int 2005; 47: 232-4. https://doi.org/10.1111/j.1442-200x.2005.02033.

[16] Hirata S, Nakamura Y, Yanagawa H. Incidence rate of recurrent Kawasaki disease and related risk factors: from the results of nationwide surveys of Kawasaki disease in Japan. Acta Paediatr 2001; 90(1): 40-4.

[17] Nakada T. Usefulness of an initial single intravenous immunoglobulin infusion with delayed use of aspirin against Kawasaki disease relapse: a single-center retrospective study. Journal of Advanced Research in Medicine $2019 ; \quad 6 \quad$ (1): $18-24$ https://doi.org/10.24321/2349.7181.201905.

[18] Egami K, Muta H, Ishii M, Suda K, Sugahara Y, Iemura M, et al. Prediction of resistance to intravenous immunoglobulin treatment in patients with Kawasaki disease, J Pediatr 2006; 149: 237-40.

[19] Kobayashi T, Inoue Y, Takeuchi K, OkadaY, Tamura K, Tomomasa $\mathrm{T}$, et al. Prediction of intravenous immunoglobulin unresponsiveness in patients with Kawasaki disease. Circulation 2006; 113: 2606-12. http://www.circulationaha.org

DOI:10.1161/CIRCULATIONAHA.105.592865.

[20] Huang X, Huang P, Zhang L, Xie X, Xia S, Gong F, et al. Is aspirin necessary in the acute phase of Kawasaki disease? J Paediatr Child Health 2018; 54(6): 661-4. doi: 10.1111/jpc.13816.

[21] Kim GB, Yu JJ, Yoon KL, Jeong SI, Song YH, Han JW, et al. Medium- or Higher Acetylsalicylic Acid for Acute Kawasaki disease and Patient Outcomes. J Pediatr 2017; 184: 125-9.

[22] Dhanrajani A, Chan M, Pau S, Ellsworth J, Petty R, Guzman J. Aspirin dose in Kawasaki disease-the ongoing battle. Arthritis Care Res (Hoboken). 2018; 70(10):1536-40 https://doi.org/10.1002/acr.23504 PMID: 29287309.

[23] Rahbarimanesh A, Taghavi-Goodarzi M, Mohammadinejad P, Zoughi J, Amiri J, Moridpour K. Comparison of high-dose versus low-dose aspirin in the management of Kawasaki disease. Indian J Pediatr. 2014; 81(12):1403. https://doi.org/10.1007/s12098-014-1437-0 PMID: 24710712

[24] Amarilyo G, Koren Y, Brik Simon D, Bar-Meir M, Bahat H, Helou $\mathrm{MH}$, et al. High-dose aspirin for Kawasaki disease: outdated myth or effective aid? Clin Exp Rheumatol. 2017; 35 Suppl 103(1):209-12. PMID: 28079513.

[25] Lee G, Lee SE, Hong YM, Sohn S. Is high-dose aspirin necessary in the acute phase of kawasaki disease? Korean Circ J. 2013; 43(3):1826. https://doi.org/10.4070/kcj.2013.43.3.182 PMID: 23613695.

[26] Chiang MH, Liu HE, Wang JL. Low-dose or no aspirin administration in acute-phase Kawasaki disease: a meta-analysis and systematic review. Archives of Disease in Children 2019. http://dx.doi.org/10.1136/archdischild-2019-318245.

[27] Tsujii N, Nogami K, Yoshizawa H, Fukuda K, Ishiguro A, Shima M, et al. Assessment of Platelet Thrombus Formation under Flow Conditions in Patients with Acute Kawasaki Disease. J Pediatr 2020; 226: 266-73. https://doi.org/10.1016/j.jpeds.2020.06.025.

[28] Branchford BR, Neeves K. New Insights into Platelet Dysfunction in Kawasaki Disease Using a Microfluidic Model of Thrombosis. J Pediatr 2020; 226: 10-1. https://doi.org/10.1016/j.jpeds.2020.08.016

[29] Wei CM, Chen HL, Lee PI, Chen CM, Ma CY, Hwu WL. Reye's syndrome developing in an infant on treatment of Kawasaki syndrome.J Paediatr Child Health. 2005;41(5-6):303-4 doi:10.1111/j.1440-1754.2005.00617.x

[30] Matsubara T, Mason W, Kashani IA, Kligerman M, Burns JC. Gastrointestinal hemorrhage complicating aspirin therapy in acute Kawasaki disease.J Pediatr. 1996;128(5, pt 1):701-3. doi:10.1016/S0022-3476(96)80140-5.

[31] McCrindle BW, Rowley AH, Newburger JW, Burns JC, Bolger AF, Gewitz MG, et al. Diagnosis, treatment, and long-term management of Kawasaki Disease: a scientific statement for health professionals from the American Heart Association. Circulation 2017; 135: e92799. DOI:10.1161/CIR.0000000000000484.

[32] Platt B, Belarski E, Manaloor J, Ofner S, Carroll AE, John CC, et al. Comparison of Risk of Recrudescent Fever in Children With Kawasaki Disease Treated With Intravenous Immunoglobulin and Low-Dose vs High-Dose Aspirin. JAMA Network Open. 2020;3(1):e1918565. doi:10.1001/jamanetworkopen.2019.18565.

[33] Sakulchit T, Benseler SM, Goldman RD. Acetylsalicylic acid for children with Kawasaki disease. Canadian Family Physician 2017; 63: $607-9$.

[34] Kuo HC, Lo MH, Hsieh KS, Guo MM, Huang YH. High-dose aspirin is associated with anemia and does not confer benefit to disease outcomes in Kawasaki disease. PLoS One. 2015; 10(12):e0144603. https://doi.org/10.1371/journal.pone.0144603 PMID: 26658843.

[35] Hsieh KS, Weng KP, Lin CC, Huang TC, Lee CL, Huang SM Treatment of acute Kawasaki disease: aspirin's role in the febrile stage revisited. Pediatrics. 2004; 114(6):e689-93. https://doi.org/10.1542/peds.2004-1037 PMID: 15545617.

[36] Nakada T. Risk stratification after initial therapy for intravenous immunoglobulin-resistant Kawasaki disease. Research Journal of Life Sciences, Bioinformatics, Pharmaceutical and Chemical Sciences 2019; 5 (5): 1-13. DOI: 10.26479/2019.0505.01.

[37] Nakada T. Background factors associated with the complications of coronary artery lesions caused by Kawasaki disease. Clinical Medicine Research 2015;4: 127-31.

[38] Bertino Jr JS, Willis ED, Reed MD, Speck WT. Salicylate hepatitis: a complication of the treatment of Kawasaki's disease. Case Reports Am J Hosp Pharm 1981; 38(8):1171-2.

[39] Japanese Circulation Society Joint Research Group. Guidelines for diagnosis and management of cardiovascular sequelae in Kawasaki disease, Pediatr Int, 47, 2005, 711-32.

[40] Liu MY, Liu HM, Wu CH, Chang CH, Huang GJ, Chen CA, et al Risk factors and implications of progressive coronary dilatation in children with Kawasaki disease. BMC Pediatrics 2017; 17: 139. 
[41] Nakada T: Inhibitory Effect of Anti-Inflammatory Drugs on the Initial Intravenous Immunoglobulin Therapy $(2 \mathrm{~g} / \mathrm{kg} /$ dose $)$ in Kawasaki Disease. International Journal of Advances in Medical Sciences 2018; 3 (5): 1-10. www.kibanresearchpublications.com.

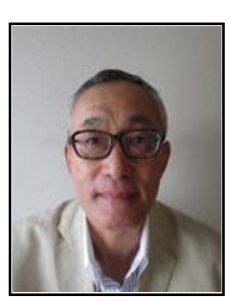

\section{Dr. T. Nakada}

Birth of place: Japan. Birth of date: 20/02/1957.

He received medical education at Hirosaki University School of Medicine. He had MD regarding pediatrics. $\mathrm{He}$ has been working as a pediatrician at Department of Pediatrics, Aomori Prefectural Central Hospital. Aomori City, Aomori Prefecture, Japan, from 1988 to the present time.

His major field of study is general pediatric cardiology: Kawasaki disease, arrhythmia, congenital heart disease, cardiomyopathy, heart disease screening, and preventive medicine. Acute phase treatment for Kawasaki disease using an initial single intravenous immunoglobulin therapy is one of his lifeworks.

Published articles

1. Nakada T. Acute phase treatment for infants younger than 1 year of age with Kawasaki disease: a single center retrospective study. Journal of Advanced Research in Medicine 2019; 6 (1): 1-6.

2. Nakada T. Risk stratification after initial therapy for intravenous immunoglobulin-resistant Kawasaki disease. Research Journal of Life Sciences, Bioinformatics, Pharmaceutical and Chemical Sciences 2019; 5 (5): $1-13$. 